\title{
The study on the optimal amount of raw materials produced by the oxidation of Chitosan on the synergy $\mathrm{HAc}-\mathrm{H}_{2} \mathrm{O}_{2}$
}

\author{
Yue-ting Lang ${ }^{1, a}$, Li-na Zheng ${ }^{1,2, b^{*}}$, Chen-xi Li ${ }^{1, c}$, Qiu-shi Wang ${ }^{1, d}$ and He-nan \\ Chen ${ }^{1, e}$ \\ ${ }^{1}$ College of Marine Technology and Environmental, Dalian Ocean University, Dalian 116023, \\ ${ }^{2}$ Key Laboratory of Nearshore Marine Environmental Research, Dalian 116023, China \\ alangyueting814@163.com, b*zln@dlou.edu.cn, \\ c1010989942@qq.com, ${ }^{\mathrm{c}} 945529598 @ q q . c o m,{ }^{\mathrm{e}} 416955893 @ q q . c o m$
}

Keywords: oligochitosan; synergistic oxidation; degradation method; dosage

Abstract. In this paper,industrial grade chitosan as the raw materials, $\mathrm{HAc}_{-} \mathrm{H}_{2} \mathrm{O}_{2}$ synergistic oxidative degradation method was used for degradation of raw materials, the influences in the reaction process with different chitosan dosage on the yield,the viscosity and the degree of deacetylation had been studied systematically.The results showed that the amount of $8 \%$ is the optimum reaction amount to the degradation of chitosan dosage.

\section{Introduction}

$\mathrm{HAc}-\mathrm{H}_{2} \mathrm{O}_{2}$ synergistic oxidative degradation of chitosan acetic acid solution is to dissolve in a certain concentration, adding a certain amount of hydrogen peroxide, reaction at a certain temperature for a certain time, then sodium hydroxide solution is used to adjust the $\mathrm{pH}$ value, In the end, the absolute ethanol with 3 5 times was used for the chitosan precipitation, drying to obtain the target product, method of collaborative $\mathrm{HAc}-\mathrm{H}_{2} \mathrm{O}_{2}$ the oxidative degradation of chitosan has the advantages of easy processing, low cost, no residue and other advantages, these features are easy to realize industrialization of environmental protection. Through the collaborative oxidation of industrial grade chitosan, this paper strives to find a high yield, low viscosity, high degree of deacetylation of Chitosan Consumption.

\section{The experimental materials and methods}

Experimental apparatus and equipment.

Table 1 Experimental apparatus and equipment

\begin{tabular}{|c|c|c|}
\hline Instrument & Model & Manufacturer \\
\hline Electronic balance & AL204 & Mettler Toledo Instruments Co. Ltd. \\
\hline Heat collector heated magnetic stirrer & DF-101S & Gongyi Yuhua Instrument Co., Ltd. \\
\hline Vacuum drying oven & Type DZF-6050 & Shanghai Heng Heng Technology Co., Ltd. \\
\hline $\mathrm{pH}$ Meter & ZD-2 & $\begin{array}{l}\text { Shanghai Hongyi instrument and Meter Co., } \\
\text { Ltd. }\end{array}$ \\
\hline Rotary viscometer & NDJ-1 type & $\begin{array}{c}\text { Shanghai Hengping Scientific Instrument } \\
\text { Co. Ltd. }\end{array}$ \\
\hline Ultrasonic cleaner & SB-5200D & $\begin{array}{c}\text { Ningbo Xinzhi biological Polytron } \\
\text { TechnologiesInc }\end{array}$ \\
\hline
\end{tabular}




\section{Experimental drugs.}

Table 2 Experimental drugs

\begin{tabular}{|c|c|c|}
\hline Drug Name & Specifications & Manufacturer \\
\hline Chitosan & $\begin{array}{c}\text { The degree of deacetylation is } \\
\text { about } 80 \%\end{array}$ & A Dalian company of Chitosan \\
\hline $30 \% \mathrm{H}_{2} \mathrm{O}_{2}$ & $\mathrm{AR}$ & $\begin{array}{l}\text { Tianjin Kermel Chemical Reagent } \\
\text { Co., Ltd. }\end{array}$ \\
\hline Glacial acetic acid & AR & $\begin{array}{c}\text { Tianjin Hengxing Chemical } \\
\text { Reagent Factory }\end{array}$ \\
\hline $\begin{array}{l}\text { Hydrochloric [chlorhydric] } \\
\text { acid }\end{array}$ & AR & $\begin{array}{c}\text { Tianjin Damao Chemical Reagent } \\
\text { Factory }\end{array}$ \\
\hline Caustic soda & $\mathrm{AR}$ & $\begin{array}{l}\text { Tianjin city Dongli District Tianda } \\
\text { Chemical Reagent Factory }\end{array}$ \\
\hline Absolute ethyl alcohol & AR & $\begin{array}{c}\text { Tianjin Damao Chemical Reagent } \\
\text { Factory }\end{array}$ \\
\hline Sodium acetate & AR & $\begin{array}{c}\text { Tianjin Damao Chemical Reagent } \\
\text { Factory }\end{array}$ \\
\hline $\begin{array}{l}\text { Mixed indicator of methyl } \\
\text { orange and aniline blue }\end{array}$ & $\begin{array}{l}\text { ( } \mathrm{g} / \mathrm{L} \text { water soluble Methyl } \\
\text { Orange: } 1 \mathrm{~g} / \mathrm{L} \text { water soluble } \\
\text { aniline blue }=1: 2 \text { volume })\end{array}$ & Laboratory preparation \\
\hline
\end{tabular}

\section{Experiment methods.}

(1) Electronic balance is used to accurately weigh a certain amount of industrial grade chitosan, added slowly to a certain concentration of acetic acid solution in the beaker, stirring constantly in the joining process, after the chitosan acetic acid solution mix well, adding once $\mathrm{H}_{2} \mathrm{O}_{2}$ needed in the experiment and put in the ultrasonic Cuncussion instrument in ultrasonic vibration 2-3 min.

(2) The magnetic vibrator in a beaker, wrap up the mouth of the beaker, and will have to set up the beaker in the water bath heating constant temperature magnetic stirrer with heating temperature specified in the rotor speed is adjusted to $120 \mathrm{r} / \mathrm{min}$, constant temperature reaction time.

(3) After the reaction was finished, the beaker was removed and the $\mathrm{pH}$ value of the reaction liquid was adjusted to $7.2-7.4$ by $2 \mathrm{~mol} / \mathrm{L} \mathrm{NaOH}$ solution.

(4) For cooling the reaction liquid to less than 50 DEG C, impurities is filtered from the reaction solution, then about 3-5 times the volume ratio of ethanol applied to the clear liquid to precipitate material.

(5) Filter again, obtained precipitate.

(6) Deionized water is used to wash the precipitate repeatedly to neutral; finally the precipitate has been dried for $12 \mathrm{~h}$ in the drying oven at 60 degrees. grinding the precipitate dried, water-soluble chitosan oligosaccharide is obtained.

\section{Results and discussion}

On the condition that the temperature is $80^{\circ} \mathrm{C}$, the concentration of acetic acid is $1 \%$, hydrogen peroxide concentration is $8 \%$, the reaction time is $3 \mathrm{~h}$, the only change is the amount of chitosan, with the requirements that the product should with high yield, low viscosity, high degree of deacetylation, optimum dosage of chitosan in $\mathrm{HAc}-\mathrm{H} 2 \mathrm{O} 2$ synergistic oxidative degradation of chitosan is obtained.

Table 3 Effect of chitosan dosage on the reaction

\begin{tabular}{cccc}
\hline w $(\%)$ & clarity & Reactive liquid color & finished color \\
\hline 4 & Slightly turbid & yellow & popcorn \\
6 & Slightly turbid & bronzing & yellow \\
8 & Slightly turbid & bronzing & brown \\
10 & muddy & brown & brown \\
12 & muddy & brown & brown \\
\hline
\end{tabular}




\section{Effect of chitosan dosage on Yield.}

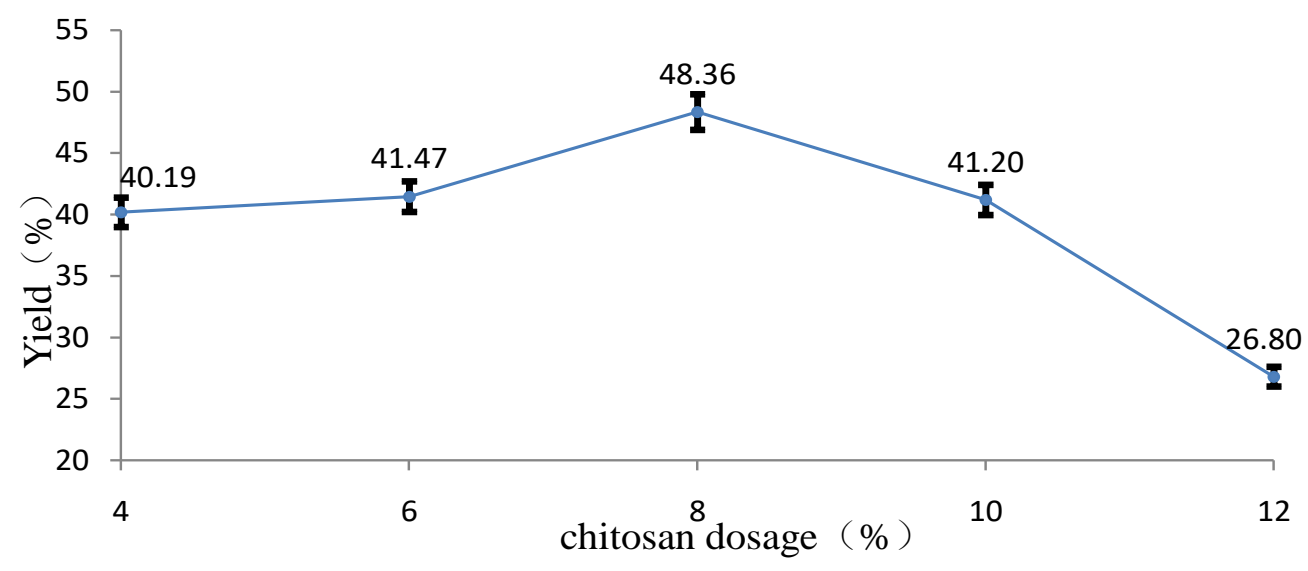

Fig.1 Effect of chitosan dosage on the yield

Analysis of Figure 1 shows that under the condition that the only change is the dosage of chitosan, the yield increased with the increasing amount of chitosan, reached the maximum when the dosage is $8 \%$, and then began to decline. When the dosage of chitosan reached $10 \%$, mixing excessive chitosan in acetic acid solution has become more difficult, can not be completely soluble in The reaction solution, In the degradation process ,chitosan can not fully contact with the oxidant, the reaction is not sufficient, the yield will be reduced.

\section{Effect of chitosan dosage on viscosity.}

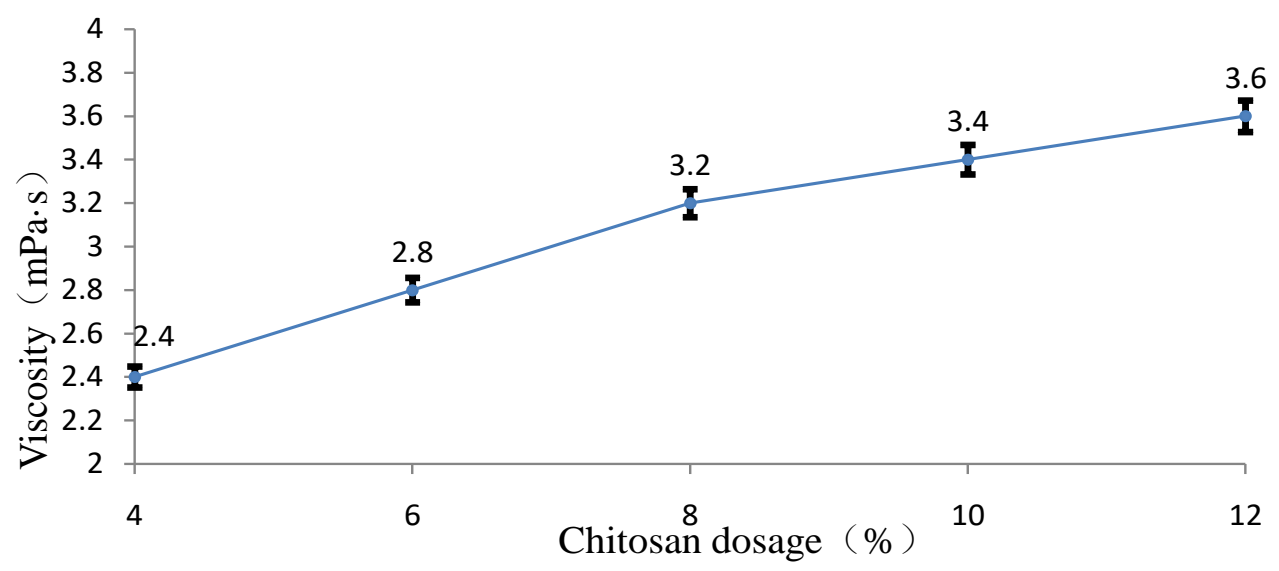

Fig. 2 Effect of chitosan dosage on viscosity

Figure 2 analysis showed that the only change in the amount of chitosan under the conditions, the viscosity increased with the increasing amount of chitosan, when the dosage was $4 \%$. The viscosity reaches the minimum value. The less dosage of chitosan ,the more soluble in acetic acid solution, the more fully contact with oxidizing agent reaction, chitosan with lower viscosity can be degraded with fully reaction.so viscosity increase with the increased of chitosan dosage . the amount of molecular weight increases with the increase of chitosan dosage as well. 


\section{Effect of chitosan dosage on deacetylation degree}

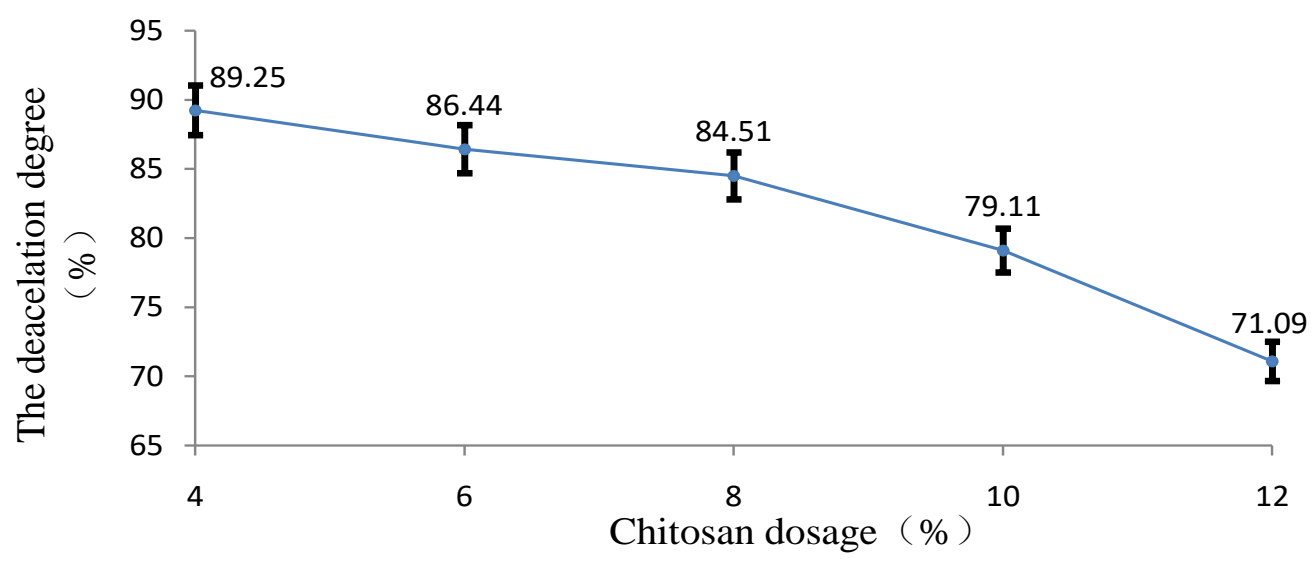

Fig.3 Effect of chitosan dosage on degree of deacetylation

Figure 3 analysis showed that under the conditions that the only change is the amount of chitosan, the degree of deacetylation decrease with the increased of chitosan dosage, when the dosage was $4 \%$,the degree of deacetylation Reaches the maximum value. The less dosage of chitosan ,the more soluble in acetic acid solution, the more fully contact with oxidizing agent reaction. chitosan with highest degree of deacetylation can be degraded with fully reaction. So the degree of deacetylation decrease with the increased dosage of chitosan.

\section{Conclusions}

The experimental results indicated that when the dosage is $6 \%$, while viscosity quality index and the degree of deacetylation of quality indicators are more remarkable than the dosage of $8 \%$ but the yield in $6 \%$ dosage is far less than of $8 \%$ dosage;And when in $10 \%$ dosage, the viscosity, degree of deacetylation and yield are all less than $6 \%$.Synthesizing several kind of situation,the amount of $8 \%$ is the most suitable dosage.

\section{Acknowledgements}

This research was financially supported by Dalian Ocean University Students' innovation and entrepreneurship program plan project(2017) and Dalian Ocean University postgraduate educational reform project(2017)（02D0201 Lina Zheng）.

\section{References}

[1] LI Da- peng, WANG Ying, LIU Wei, MENG Ling- wei. Preparation of Chitosan Oligosaccharide by Ultrasonic Degradation MethodBand the Antimicrobial Effect[J].Academic Periodical of Farm Products Processing, 2013, (7) 332:10-11.

[2] Li Xin, Zhang Liang, Yang Meng-shi, Chu Xiu-Xiang, Xu Chan, Chen Liang, Wang Yue-Yue. Theoretical study on geometry and physical and chemical properties of oligochitosan [J]. Acta Physica. Sinica,2014, (7), 76102

[3] Ou Chun-yan, Li Lin-tong. Recent Progress of study on Degradation of Chitosan [J]. Guangzhou Chemical Industry, 2013,41 (6): 13-15.

[4] Yao Bang-tao Chen Ji-wei. Study on the Preparation of Soluble Chitosan through the Chitosan Degraded by Hydrogen Peroxide [J]. Paper Science\&Technology ,2015, 34 (6): 60-62. 
[5] Zhang Yong, Zhang Xiaowei, Li Yaming. Study on the preparation of chitosan oligomers by hydrogen peroxide degradation of chitosan [J]. Anhui agricultural science and technology, 2011, 39 (21): 13060-13062. 